\title{
Exposure-time and the apparent length of an illuminated rotating arc-line
}

\author{
GORDON STANLEY \\ UNIVERSITY OF NEW ENGLAND, AUSTRALIA ${ }^{1}$
}

Eighteen male Ss made estimates of the apparent length of an illuminated arc-line rotating at $75 \mathrm{rpm}$. Two arc-lengths $(6$ and $12 \mathrm{~cm}$ ) were exposed for 200, 100 and $40 \mathrm{msec}$. Apparent shrinkage occurred for both arc-lengths at $200 \mathrm{msec}$, but not at the other exposures. This result was interpreted as indicating that stimulation of a certain proportion of retinal units during a specific time interval is a necessary condition for the contraction effect to occur.

An illuminated arc-line on dark surrounds viewed when rotating at a constant speed around a central fixation point appears much shorter than when viewed stationary. This finding was first reported in the literature by Ansbacher (1938, 1944), although Ansbacher attributed the discovery of the phenomenon to Harold C. Brown, who apparently never published his findings.

In Ansbacher's (1944) investigation of the shrinkage effect, the experimental task required of the $S$ was to compare the apparent length of an arc-line standard on a rotating disc with a stationary straight line comparison stimulus mounted at the center of the disc. The path of rotation of the arc-line subtended a visual angle of $12 \mathrm{deg}$ to the fixation point located at the center of the straight line comparison stimulus. Ansbacher reported that when the disc was rotating at $78 \mathrm{rpm}$ an arc-line of $13 \mathrm{~cm}$ length appeared only one-eight of its stationary length. Beyond $78 \mathrm{rpm}$ there seemed to be more than one arc present and finally these multiple arcs fused to give a circle of light.

Ansbacher (1944) reported that the effect was due to contrast effects arising from the re-stimulation of retinal points occurring as the arc moves around its path of rotation. Further accounts of the phenomenon in terms of the process of excitation and inhibition have been discussed by Marshall and Stanley (1964). These accounts also presuppose that the effect is related to the continual re-stimulation of retinal units.

Stanley (1964) reported that small gaps in the arc did not appreciably reduce the shrinkage effect and subsequently suggested that the effect is based on brightness integration occurring over a given temporal/spatial interval (Stanley, 1967a, 1967b). On the basis of this account, the number of retinal units responding maximally at any given duration is the assumed neurophysiological correlate of apparent length. Under conditions of rotation this number is less than occurs when the arc is stationary, because of the sequential nature of the stimulation. If the duration of observation is decreased by tachistoscopic exposure, then the effect should decrease because, in the limit, movement is "stopped" and simultaneous rather than successive stimulation of retinal units would occur.

The present experiment was designed to investigate the effect of reducing the duration of observation of the arc-line during its course of rotation. It was predicted that as duration of exposure decreased, apparent length would increase.

\section{Subjects}

Ss were 18 male medical students from the University of Western Australia. All were naive with respect to the Ansbacher effect and were screened on the acuity tests of the Bausch Lomb Orthorater.

\section{Apparatus}

The apparatus used was a modification of the Ansbacher (1944) apparatus. It consisted of a disc $50 \mathrm{~cm}$ in diameter with an illuminated arc-line (luminance $=100 \mathrm{ft}-\mathrm{L}$ ) $0.4 \mathrm{~cm}$ wide, located at a radial distance of $21 \mathrm{~cm}$ from the center of the disc. At the center of the disc there was a stationary illuminated (luminance $=100 \mathrm{ft}-\mathrm{L}$ ) horizontal straight line $0.4 \mathrm{~cm}$ wide with a small black dot located centrally. On this apparatus the length of both the stationary center line and the outside arc-line could be varied by independent cables moving shutters which covered or uncovered the front and rear of the line or arc. For this experiment the center line was kept constant in length at $3 \mathrm{~cm}$, while the arc was varied in length according to the experimental conditions. The disc was rotated at a constant speed of $75 \mathrm{rpm}$ and was located at $100 \mathrm{~cm}$ from $\mathrm{S}$, who was seated in a subject booth.

Variation in speed of exposure of the rotating arc-line was obtained by having the $S$ view the apparatus through an Alphax shutter. The shutter was not synchronized with the rotation of the disc so on any given trial the arc could appear in any quadrant of the visual field.

\section{Procedure}

Two lengths of line, $6 \mathrm{~cm}$ and $12 \mathrm{~cm}$, were each presented at three exposures, 40, 100, and 200 msec. Each of these conditions was repeated 10 times. Order of presentation of conditions and trials was randomized.

The Ss were tested individually and when seated in the subject booth were read the following instructions: "When the shutter opens you will see a black disc which has an illuminated straight horizontal line in the center and a moving illuminated arc-line out at the periphery, i.e., near the circumference of the disc. I want you to keep fixating a black spot in the middle of the center line while the shutter is open, i.e., you should not allow your eyes to drift out and look directly at the outside line. You will be required to estimate the length of the outside line in inches or fractions of an inch, and you may use the center line as your reference. Make quick judgments; do not deliberate in any way. We are not interested in how correctly you judge the actual length of the outside arc, we only want to know how it looks to you. From time to time the outside arc will be changed in length. Remember you are to estimate the length of the outside arc-line in inches or fractions of an inch, but you must not look directly at the arc-line, you should keep fixating the black spot in the middle of the center line. The shutter will only open for a short time and I will warn you by saying "ready" and then "now" for each exposure."

\section{RESULTS}

Table 1 lists the group mean estimates of each length of line for each duration of exposure. These estimates were based on the mean estimates of each condition for each $S$ and are expressed in centimeters to enable ready comparison with the lengths of the standards. As can be seen from this table there is a clear tendency for apparent length to increase as duration of exposure decreases, with a marked change from 200 to $100 \mathrm{msec}$.

To test the significance of this effect an analysis of variance for a two-factor repeated measurements design was carried out

Table 1

Group Mean Estimates of Arc-Length for Each Duration of Exposure

\begin{tabular}{ccc} 
Exposure (msec) & $6 \mathrm{~cm} \mathrm{std}$. & $12 \mathrm{~cm} \mathrm{std}$ \\
\hline 200 & 2.403 & 2.916 \\
100 & 6.411 & 10.068 \\
40 & 6.966 & 11.349 \\
\hline
\end{tabular}


according to Myer's (1966, p. 171) paradigm. The analysis revealed a significant duration effect $(F=94.81$, $d f=2 / 34$, $\mathrm{p}<.001)$, a significant length effect $(\mathrm{F}=187.54$, df $=1 / 17$, $\mathrm{p}<.001$ ), and a significant Duration by Length interaction $(F=25.19, \mathrm{df}=2 / 34, \mathrm{p}<.001)$.

\section{DISCUSSION}

The results confirm the prediction that as duration of exposure decreases, apparent length increases. The shrinkage effect occurs clearly at $200 \mathrm{msec}$, while for the 100 and $40 \mathrm{msec}$ duration there is little shrinkage and little difference due to further change in duration.

At $100 \mathrm{msec}$ the arcs have moved through $12.5 \%$ of the path of rotation, and at $200 \mathrm{msec}$ through $25 \%$. This finding, together with the fact that shrinkage increases as speed of rotation increases up to $78 \mathrm{rpm}$ (Ansbacher, 1944; Stanley, in press), suggests that stimulation of a certain proportion of retinal units during a specific time interval is a necessary condition for the contraction effect to occur.

At $200 \mathrm{msec}$ the apparent length of the $6 \mathrm{~cm}$ arc is $40 \%$ of its physical length whereas the apparent length of the $12 \mathrm{~cm}$ arc is $24 \%$ of its physical length. This supports the previous finding of Stanley (1966) that under conditions where apparent shrinkage occurs, greater shrinkage occurs with larger arcs. As it is assumed that, for a given retinal unit, the leading edge of the arc-line corresponds to light onset and the trailing edge to light offset, arc-length may be considered to alter duration of stimulation of the retinal unit. The present results thus support the conclusion that duration of stimulation of the retinal units is also an important parameter of the shrinkage effect.

\section{REFERENCES}

ANSBACHER, H. L. Further investigation of the Harold C. Brown shrinkage phenomenon: a new approach to the study of the perception of movement. Psychol Bulh, 1938, 35, 701.

ANSBACHER, H. L. Distortion in the perception of real movement. J. exp. Psychol, 1944, 34, 1-23.

MARSHALL, A. J., \& STANLEY, G. The apparent length of light and dark arcs seen peripherally in rotary motion. Austral. J. Psychol, 1964, 16, 120-128.

MYERS, J. L. Fundamentals of experimental design. Boston: Allyn \& Bacon, 1966.

ST ANLEY, G. A study of some variables influencing the Ansbacher shrinkage effect. Acta. Psychol, 1964, 22, 109-118.

STANLEY, G. Apparent shrinkage of a rotating arc as a function of luminance relations between figure and surround. Acta. Psychol., 1966, 25, 357-364.

STANLEY, G. Apparent brightness of a rotating arc-line as a function of speed of rotation. Acta. Psychol, 1967a, 26, 17-21.

STANLEY, G. Light summation and the perceived length of moving lines. Acta. Psy chol, 1967b, 26, 260-264.

STANLEY, G. Apparent length of a rotating arc-line as a function of speed of rotation, Acta. Psycho., in press.

\section{NOTE}

1. The data were collected while the author was at the University of Western Australia. Miss S. P. May of the University of New England assisted in data-analysis.

(Accepted for publication April 3, 1968.) 